\title{
Material Property and Stress Field near Notch Tip in Steel Plate under High Electric Current
}

\author{
Thomas Jin-Chee Liu, Ji-Fu Tseng, Chun-Der Cheng \\ Department of Mechanical Engineering, Ming Chi University of Technology, Taishan, New Taipei City, Taiwan
}

\begin{abstract}
Under high electric current, the material property and stress field near the notch tip in the stainless steel plate have been investigated. Using the numerical and experimental methods, the electric current density, temperature, stress, grain image and micro hardness are obtained. Also, the melting and heat-affected zones at the notch tip are investigated. At the tip region, the hardness value improves and the compressive residual stress occurs. This result can reduce the stress level and prevent from the crack initiation when the plate is subjected to the tensile load.
\end{abstract}

\section{Introduction}

As shown in Fig. 1, the electro-thermo-structural coupled-field analyses of the fractured metal structure have been reported in the past references [1-6]. This problem concerns the crack detection and crack arrest [6]. Under low electric current, there is a hot spot (shown in Fig. 1) at the crack tip and it can be detected by the infrared camera. However, under high electric current, the hot spot can melt and a crack tip hole can be made. The hole can stop the crack propagation.

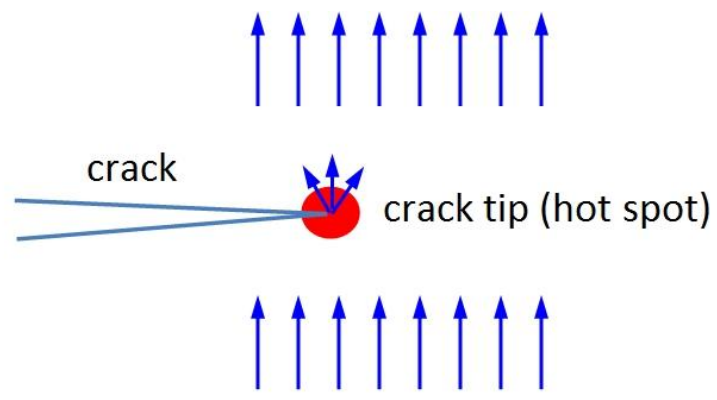

\section{electric current}

Figure. 1. Coupled-field and hot spot at crack tip.

This paper studies the electro-thermo-structural coupled-field problem of the steel plate with a notch. Using the numerical and experimental methods, the electric current density, temperature, stress, grain image and micro hardness will be obtained. Similar to the crack problem, the concentrations of the electric current and stress exist at the notch tip. Especially, the material property and stress field near the notch tip will be discussed in this paper.

\section{Problem definition}

In Fig. 2, it shows the sample and configuration of this study. The sample is a steel plate with a notch. The main dimensions of the plate are $L, W, a, \alpha$, and thickness $e$. The electric power equipment provides a current $I_{0}$. The current will induce the temperature field and thermal tress/deformation. The sample is made of the SUS 304 stainless steel. The material properties are listed in Table 1. The elasto-plastic stress-strain relation with the tangent modulus $E_{T}=0.4 E$ is considered in the analysis.

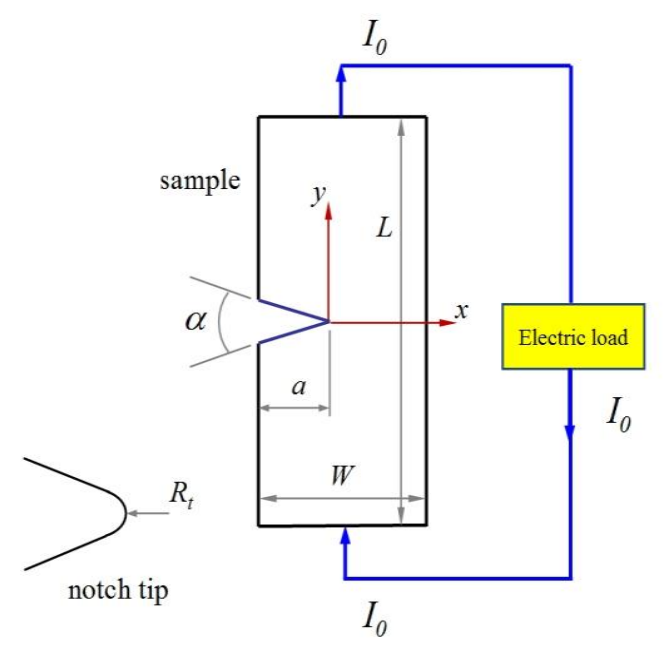

Figure. 2. Problem definition.

\section{Experimental and numerical analyses}

Fig. 3 shows the experimental equipment of this study. The equipment is modified from the resistance spot welding (RSW) machine. The sample (steel plate) is fixed on two electrodes. The electric power supplier 
provides the high electric current. The dimensions of the sample are $L=0.1 \mathrm{~m}, W=0.008 \mathrm{~m}, a=0.004 \mathrm{~m}, e=0.001 \mathrm{~m}$, $\alpha=20^{\circ}$, and $R_{t}=0.0002 \mathrm{~m}$.

The finite element method and the software ANSYS are adopted for the numerical simulation. In Fig. 4, it shows the finite element model of the steel plate. The model is constructed by the SOLID226 element associated with the electro-thermo-structural coupledfield analysis. The following conditions are considered in the finite element analysis:

(1) Electro-thermo-structural coupled-field.

(2) Three-dimensional degrees-of-freedom (DOFs).

(3) Transient heat transfer (initial condition: $25^{\circ} \mathrm{C}$ ).

(4) Convection on air/steel interface (natural convection coefficient: $\left.25 \mathrm{~W} /\left(\mathrm{m}^{2}-\mathrm{K}\right)\right)$.

(5) Steady electric current (DC current).

(6) Elasto-plastic material property.

Table 1. Material data of SUS 304 stainless steel [7,8].

\begin{tabular}{|c|c|c|c|c|c|c|}
\hline Temperature ( $(\mathrm{C})$ & $\begin{array}{l}\text { Young's modulus } \\
E\left(\mathrm{GPa}^{2}\right)\end{array}$ & $\begin{array}{l}\text { Yielding gtength } \\
S_{r}\left(M_{P}\right)\end{array}$ & $\begin{array}{l}\text { Coefficient } \\
\text { of themanal expansion } \\
\alpha(1 / 0)\end{array}$ & 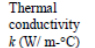 & $\begin{array}{l}\begin{array}{l}\text { ppecific } \\
\text { heat } \\
C_{C}\left(J / k g .{ }^{\circ} C\right)\end{array}\end{array}$ & $\begin{array}{l}\text { Resistivity } \\
\rho(\Omega-m)\end{array}$ \\
\hline$\frac{20}{20}$ & 193 & 290 & & & & $7.2 \times 107$ \\
\hline 年 &. &. & & & 990 & $7.8 \times 107$ \\
\hline $\begin{array}{l}93 \\
100 \\
\end{array}$ & 192 & & $i_{163 \times 3 \times 0}$ & ${ }_{162}$ & & : \\
\hline 149 & 187 & 182 & ier & : & 892 & $86 \times 107^{2}$ \\
\hline $\begin{array}{l}204 \\
2060\end{array}$ & 183 & iso & & : & & \\
\hline 3000 & 179 &. & $17,1 \times 10^{\circ}$ & & & \\
\hline 320 & m & . & & $\therefore$ & 557 & $9.5 \times 100$ \\
\hline $\begin{array}{l}371 \\
400 \\
400\end{array}$ & 170 & ${ }^{134}$ & $17.6 \times 100$ & & : & \\
\hline $\begin{array}{l}4.47 \\
430\end{array}$ &.$^{168}$ & & & : & 574 & $102 \times 10^{-7}$ \\
\hline $\begin{array}{c}482 \\
500\end{array}$ & . 180 &.$^{125}$ & $180 \times 10^{\circ}$ & 21.5 & : & \\
\hline $\begin{array}{l}588 \\
5 \neq 0\end{array}$ & ${ }^{135}$ & & & $:$ & 586 & $10.8 \times 10.7$ \\
\hline $\begin{array}{l}5093 \\
5000\end{array}$ & ${ }^{150}$ & ${ }^{113}$ & $18.3 \times 104$ & : & & . \\
\hline $\begin{array}{l}649 \\
6950\end{array}$ & 145 & & & : & 599 & $i_{11.4 \times 10}$ \\
\hline $\begin{array}{l}700 \\
704\end{array}$ & 141 & 95 & 19.0.410" & : & . & \\
\hline 760 & 134 & & & - & 620 & $11.8 \times 10-7$ \\
\hline $\begin{array}{l}8 \\
8160 \\
816\end{array}$ & 125 & 68 & $20.0 \times 10^{\circ}$ & ${ }^{\circ}$ & $\dot{0}$ & : \\
\hline
\end{tabular}

Poisson's ratio $v=0.29$, density $\beta=8000 \mathrm{~kg} / \mathrm{m}^{3}$, melting point $=$ $1400{ }^{\circ} \mathrm{C}$.
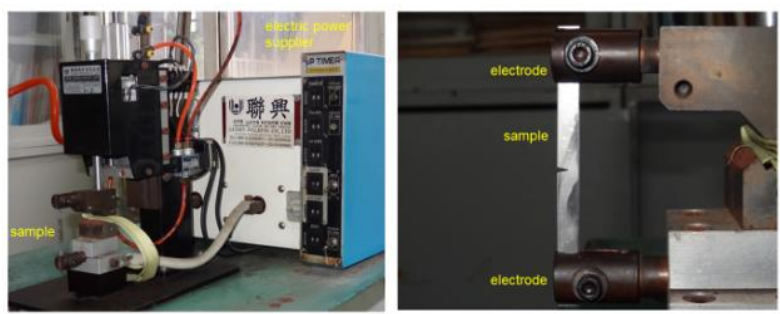

Figure. 3. Experimental equipment

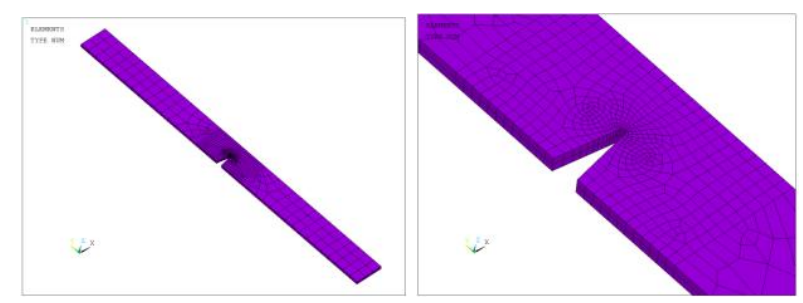

Figure. 4. Finite element model.

\section{Results and discussions}

As shown in Fig. 3, the steel plate is fixed on two electrodes of the RSW machine. The high electric current $I_{0}=600$ A (RMS value) is applied on the steel plate with the operating time $t_{p}$. In Fig. 5, the hot spot is seen at the notch tip during the high electric load. The hot spot is due to the electric current density concentration and Joule heating effect at the notch tip.

By controlling $t_{p}$, different situations can be seen at the notch tip. In Fig. 6, it represents four situations: (a) surface change, (b) melting/solidification without hole, (c) melting/solidification with hole, (d) burning and breaking. When the electric power is provided enough, the melting zone occurs at the notch tip. Furthermore, the solidification, heat-affected zone (HAZ), shrinking hole or breaking failure can be investigated.

The material property around the notch tip is modified under high electric load and high temperature. The sample in Fig. 6(b) is analyzed by the microscopic investigation and nano- indentation. In Fig. 7, it shows the grain images obtained by the microscope. The grain size in HAZ becomes smaller after high electric load $\left(I_{0}=600 \mathrm{~A}, t_{p}=0.2333 \mathrm{~s}\right)$. Using the nano-indentation method, the hardness of the original material and HAZ are obtained. The hardness values are $2.59 \mathrm{GPa}$ and 3.44 $\mathrm{GPa}$, respectively. At the notch tip region, the hardness improves so that the strength increases.
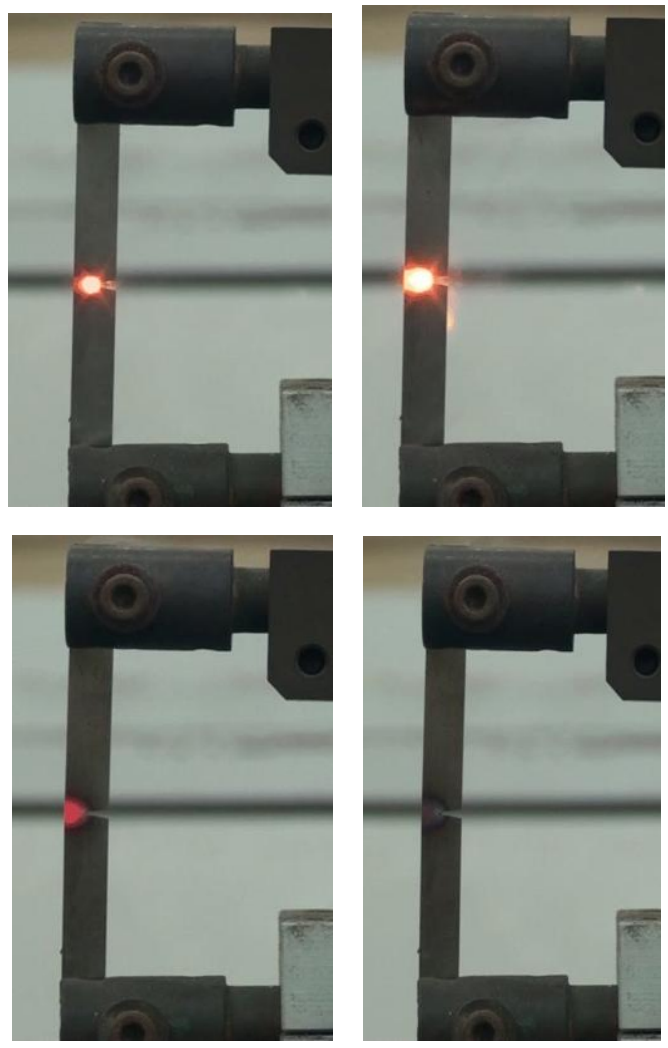

Figure. 5. Hot spot at notch tip under high current $(\mathrm{tp}=0.2666 \mathrm{~s})$. 


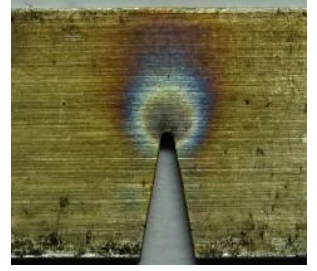

(a) $t_{p}=0.1667 \mathrm{~s}$

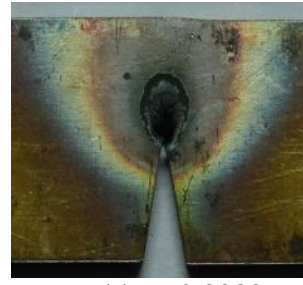

(c) $t_{p}=0.3333 \mathrm{~s}$

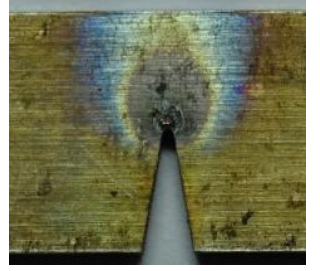

(b) $t_{p}=0.2333 \mathrm{~s}$

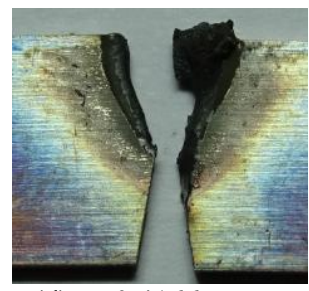

(d) $t_{p}=0.4166 \mathrm{~s}$
Figure. 6. Different situations at notch tip under high current.

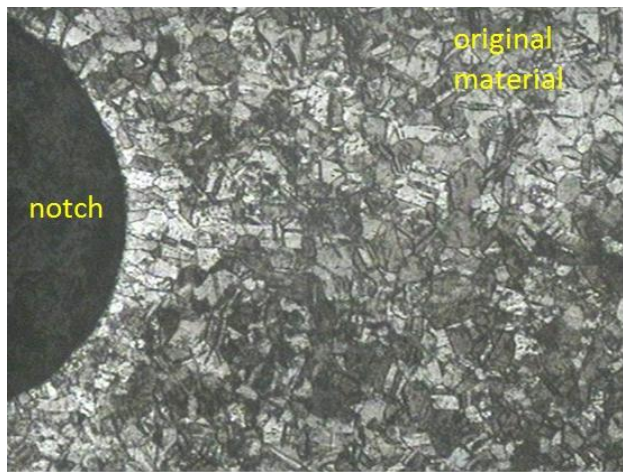

(a)

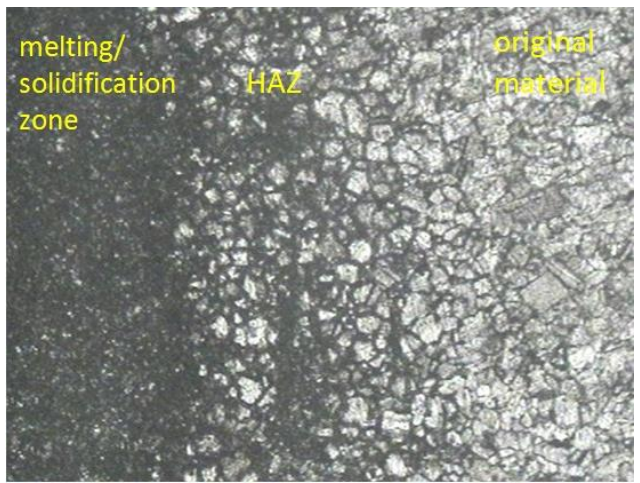

(b)

Figure. 7. Grain images. (a: original steel plate, b: plate under high current) (240X)

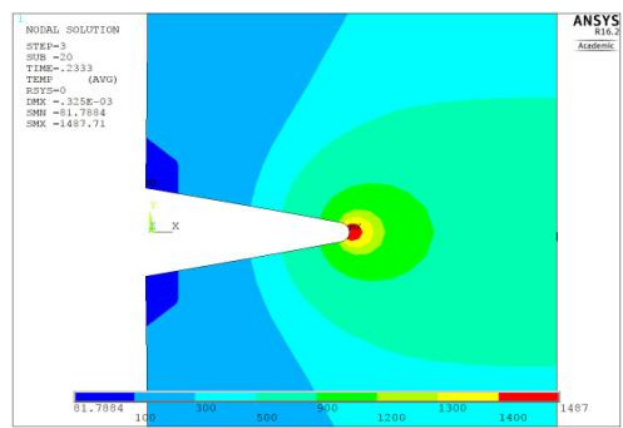

(a)

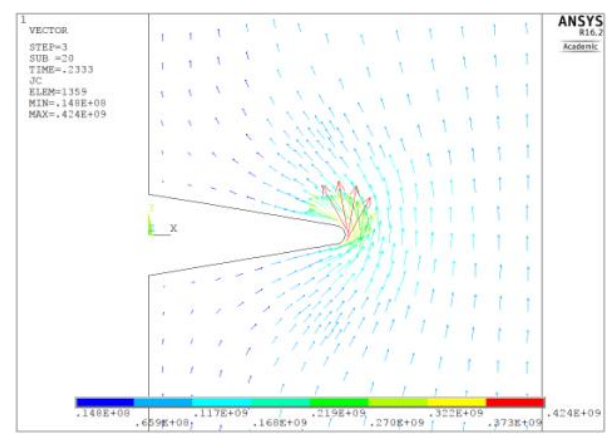

(b)

Figure. 8. (a) temperature field (units: ${ }^{\circ} \mathrm{C}$ ), (b) electric current density field (units: $\mathrm{A} / \mathrm{m}^{2}$ ).

The finite element analysis is used to study the electric current density, temperature and stress fields. Under $I_{0}=600 \mathrm{~A}$ and $t_{p}=0.2333 \mathrm{~s}$, the results are shown in Fig. 8. It is investigated that a hot spot exists at the notch tip zone. Also, it shows the electric current density concentration at the notch tip. The temperature contour is identical to the photo in Fig. 6(b).

In addition, the residual stress state is also studied. In the finite element analysis, the cooling process is considered after the electric load is removed. In Fig. 9(a), it shows the residual stress $\sigma_{y}$ at $t=120 \mathrm{~s}$ (cooling time is about $120 \mathrm{~s}$ ). In the region near the notch tip, the compressive residual stress state is found. Also, the stress history at the notch tip is shown in Fig. 9(b). This result can reduce the tensile stress level and prevent from the crack initiation when the plate is subjected to the tensile load.

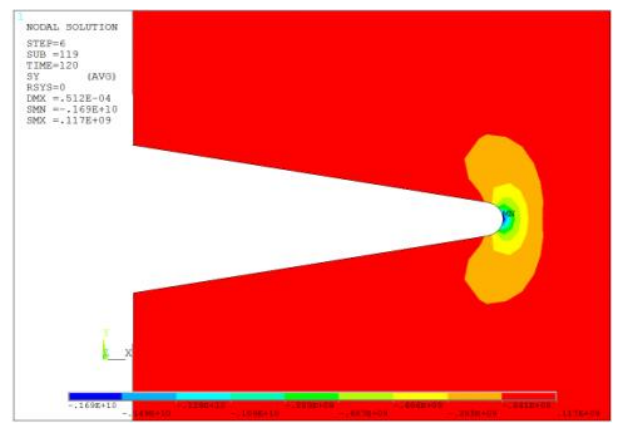

(a)

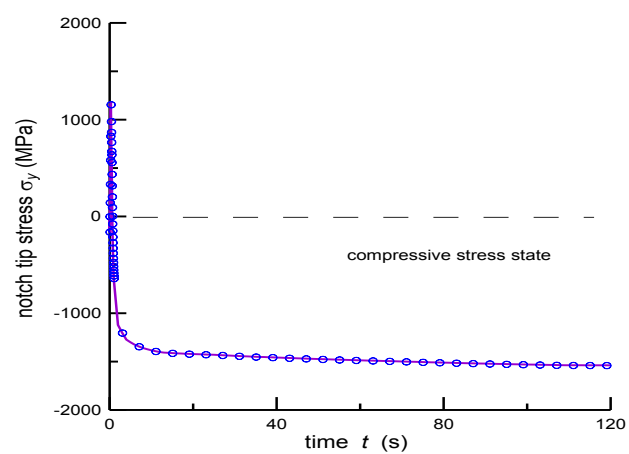

(b)

Figure. 9. (a) Contour of residual stress $\sigma_{y}$ (units: Pa), (b) stress history at notch tip. 


\section{Conclusions}

At the notch tip region, the hardness value improves and the compressive residual stress occurs under the high electric current. This result can reduce the stress level and prevent from the crack initiation when the plate is subjected to the tensile load. This conclusion can be applied on the improvement of the structure with notches.

\section{Acknowledgment}

The authors would like to thank the Ministry of Science and Technology in Taiwan for the financial support under contract numbers MOST 104-2221-E-131-030 and MOST 105-2221-E-131-014.

\section{References}

1. V.Z. Parton and B.A. Kudryavtsev: Electromagnetoelasticity (Gordon and Breach, New York 1988).

2. Z. Qin, L. Librescu and D. Hasanyan: J. Therm. Stress Vol. 30 (2007), p. 623

3. Y.M. Fu, X.Z. Bai, G.Y. Qiao, Y.D. Hu and J.Y. Luan: Mater. Sci. Tech. Vol. 17 (2001), p. 1653

4. T.J.C. Liu: Eng. Fract. Mech. Vol. 78 (2011), p. 666

5. T.J.C. Liu: Eng. Fract. Mech. Vol. 123 (2014), p. 2

6. T.J.C. Liu, in: Encyclopedia of Thermal Stresses, edited by R.B. Hetnarski, Springer Science + Business Media Dordrecht, Berlin (2014).

7. Online Materials Information Resource - MatWeb (MatWeb, LLC., USA 2016). (http://matweb.com/)

8. High-Temperature Characteristics of Stainless Steels (American Iron and Steel Institute, USA 2006). 